\title{
MOTIVATION OF HEALTH CARE WORKERS IN TANZANIA: A CASE STUDY OF MUHIMBILI NATIONAL HOSPITAL
}

\author{
Melkidezek T. Leshabari ${ }^{1}$, Eustace P.Y.Muhondwa ${ }^{1}$, M.A.Mwangu ${ }^{2}$, Naboth A.A.Mbembati ${ }^{3}$
}

Abstract

Objective: The Tanzanian health system is currently undergoing major reforms. As part of this, a study was commissioned into the delivery of services and care at the Muhimbili National Hospital.. One of the main components of this comprehensive study was to measure the extent to which workers in the hospital were satisfied with the tasks they performed and to identify factors associated with low motivation in the workplace.

Methods: This was a cross sectional study involving a sample of 448 hospital workers. Stratified sampling was used to randomly pick $20 \%$ of: doctors, nursing staff, auxiliary clinical workers and other administrative and supporting staff. About $44 \%$ of the workers were female.

Results: Almost half of both doctors and nurses were not satisfied with their jobs, as was the case for $67 \%$ of auxiliary clinical staff and $39 \%$ of supporting staff. This dissatisfaction was multi-factorial in origin. Amongst the contributing factors reported were low salary levels, the frequent unavailability of necessary equipment and consumables to ensure proper patient care, inadequate performance evaluation and feedback, poor communication channels in different organizational units and between workers and management, lack of participation in decision-making processes, and a general lack of concern for workers welfare by the hospital management.

Conclusions: Many workers at all levels in the hospital were not satisfied with the tasks they performed due to a variety of factors. Based on the study findings, several recommendations were made including setting defined job criteria and description of tasks for all staff, improving availability and quality of working gear for the hospital, the introduction of a reward system commensurate with performance, improved communication at all levels, and introduction of measures to demonstrate concern for the workers' welfare.

Keywords: Job satisfaction, health worker motivation, performance review, health personnel, Tanzanian health system, referral hospitals human resource mix.

\section{Introduction}

The Tanzanian health system is currently undergoing major reforms. As part of this, the former Muhimbili Medical Centre (MMC), a state-run organization under the Ministry of Health, was split into the Muhimbili National Hospital (MNH) under the Ministry of Health, and the Muhimbili University College of Health Sciences (MUCHS) under the Ministry of Science Technology and Higher Education. MUCHS was a College of the University of Dar es Salaam which formerly was operated by the MMC. Under this arrangement, all financial, personnel and management issues were handled by the MMC, whilst the University Senate managed all academic issues. The original merging of the College and Hospital activities aimed at more efficient utilization of academic staff in the clinical departments for patient care and the hospital facilities for teaching purposes. However, declining resources for the teaching programmes over the last 15 years and a disparity in the primary missions of the clinical and academic arms of the organization led to problems with this combined approach. As part of health reforms taking place in the country, MMC was split into Muhimbili National Hospital and Muhimbili University College of Health Sciences in order for each organization to address its primary mission. The College was later upgraded into an independent University (Muhimbili University of Health and Allied Sciences) with effect from July, 2007.

Correspondence to: M.T.Leshabari, P.O.BOX 65015 Dar es Salaam Tanzania Email:mleshabari@muhas.ac.tz

'Dept of Behavioural Sciences, School of Public Health and Social Sciences, Muhimbili University of Health and Allied Sciences: ${ }^{2}$ Dept of Development Studies, MUHAS, Department of Surgery, School of Medicine, MUHAS, Dar es Salaam, Tanzania
The African continent is currently facing serious human resource crisis in the health sector (1-5). These severe human resource shortages have affected the ability of many countries to initiate and sustain credible health services. Although several reforms and policies have been developed to address health problems in the continent (68 ), little attention has been given to required human resources and their motivation (1,9-10).

The quality of performance in health facilities to a large extent depends on available human resource mix and their motivation (11). The workforce which is one of the most important inputs to any health system has a strong impact on the performance of health facilities (12). Despite the existence of several theories of motivation in the work place (13-15), little empirical data is available on the extent to which these theories have been used to address motivation related issues among health care workers in Africa even though there is overwhelming evidence of attrition $(5,14)$.

There are a few studies which have addressed motivation of health workers in Tanzania (16). Motivational issues among workers at the MNH can be largely transposed to the Tanzanian health system as a whole, in both rural and urban areas. Indeed, low motivation in the workplace contributes towards the braindrain of the health manpower in Africa from one country to another or from rural to urban areas within the same country (1,3,8,17-20). Sub-Saharan Africa has the lowest health worker to population ratio in the world, a situation that has recently worsened partially due to migration of the few available workers to other countries (2,21-22). For example, one report of 2002 shows that out of the 150 medical officers who were trained in three medical schools in Ghana, $50 \%$ left the country within the second year and $80 \%$ left by the fifth year (23). Seventy percent of doctors trained in Zimbabwe in the 1990s have migrated out of the 
country (3). The health work force in Tanzania declined by over $35 \%$ between $1994 / 95$ and 2005/2006 partially due to migration out of the country (24). Tanzania has been training medical doctors since 1963, but mapping surveys in 2006 revealed that only 1,339 doctors were in the country and 455 of them were working in the private sector (25).

According to the 2005 proposed national staffing levels for the health sector, Tanzania should have 125,924 health workers but only 35,202 were available representing a deficit of over 72 per cent (25). This deficit would be even more serious due to current proposals to build one hospital for each district, one health centre for each administrative ward and a dispensary for each village. Little is known about the quality of health services provided by existing few workers and the level of motivation in their respective work stations.

It is also important to note that despite of decades of effort to provide effective, equitable and affordable health care services, health indices in Africa have either remained unchanged or declined $(7,21,26,27)$. Surprisingly, financial and technological resources are not the major barriers to improving the health system in Africa. Instead, poor implementation of systemic improvements is to blame, and personnel motivation is a key component in this functional failure.

The motivation of workers is influenced by several factors. Financial resources in terms of salary and other fringe benefits is just one of the elements $(14,15,20,28)$. $\mathrm{MNH}$ is the only national referral hospital in Tanzania and has the highest concentration of health experts and specialists of any hospital. However, when this study was conducted salaries were so low that even the clinicians had to seek additional employment in private hospitals to supplement their income. Until recently the starting salary of doctors was less than $\$ 200$ per month. Several reforms were introduced at $\mathrm{MNH}$ to improve the situation including benefits for doctors attending meetings and workshops, to be later replaced by a promise of performance-linked salary increases. The impact of all these efforts is yet to be fully assessed, but future strikes by workers due to grievances associated with low salaries and unfavourable working conditions are still a real possibility for the hospital system. Indeed at the time of writing this paper (December 2005) junior doctors and some nurses were suspended from duty due to strikes whose root cause was low salaries.

Apart from low salaries, lack of motivation in the workplace can also arise from several other factors, including lack of positive acknowledgment and reward for good service, punitive measures for even infrequent mistakes, and a lack of communication between management and staff. All of these factors contribute to a general lack of work satisfaction, as well as disharmony between managers and workers.

The extent to which workers at MNH are satisfied with the tasks they do and their working environment, and how these factors affect staff performance has not been empirically documented. Therefore, the Axios Foundation initiated the present study as part of a major reform process financed by the Government of Tanzania and
Abbott Fund that included broad infrastructural and managerial changes.

This study was part of a comprehensive baseline assessment that also included studies on organization and management, patient satisfaction, patient referrals, surgery and laboratory performance indicators, health facility utilization, and drug and investigation ordering. These studies were to be repeated in 2007, using comparable methodology, allowing an assessment of the impact of the current reforms at Muhimbili National Hospital. Study results could inform similar hospital reform processes in other developing countries.

\section{Methods}

This study was conducted in 2003-2004 with the $\mathrm{MNH}$ staff as the target population. At that time, all workers were employed by the former MMC, including employees of MUCHS. It is important to note that the Transition Management Committee, whose responsibility was to advise the government on the distribution of assets and personnel to the new, separate institutions, was yet to complete their task when this study was conducted.

A structured interview schedule with four major sections was developed to generate the required data. The interview schedule had questions which focused on: task description, performance evaluation and use of rewards and punishment; participation in decision making; frequency of supervision and feedback and issues related to workers' welfare. The questions were developed in English and later translated into Kiswahili the Tanzanian national language which is commonly spoken by nearly every body in the country.

Data were collected by research assistants who were trained for five days including pre-testing of the instruments. Completed interviews were checked on a daily basis by the first author for accuracy and any problems identified were discussed in order to maximize the quality of the data generated. The data were computerized and analyzed using SPSS version 10 .

A list of 2865 workers was obtained from the hospital management and a sampling frame was developed to identify employees of the Hospital. The list was subdivided into four major categories: (1) doctors who were doing clinical work in the hospital; (2) all nursing staff involved in hospital care; (3) other clinical support staff such as pharmacists, radiological assistants, laboratory technicians and physiotherapists; and, (4) administrative and other support staff.

Despite steps taken to identify workers who belonged to the hospital by eliminating those working in the College (academic staff in basic sciences departments and workers in other departments of the College), there were some workers who provided services to both the College and the Hospital. For example, some members of staff in the Departments of Parasitology/ Medical Entomology and Microbiology/Immunology had roles in both the Hospital and the University; such workers were included in the sampling frame for the study. Eligibility for the study was defined as any worker who was providing services to the hospital. Employment of new staff in government 
institutions including this hospital had stopped for over ten years due to structural changes which were taking place in the government system (25).

A total of 2310 workers were deemed as eligible for this study. Stratified sampling was used to randomly pick 20 percent of each category of workers. The final sample size was 462 respondents.

Permission for conducting the study was first obtained from Muhimbili University of Health and Allied Sciences Research Ethics Committee. Before contacting eligible workers from various departments in the hospital, consent for doing the study was also obtained from the hospital management. Each selected study participant was informed about the purpose of the study and also told they were free to refuse to participate or answer any of the questions without any consequences.

Six workers refused to participate in the survey, and eight workers could not be reached during the data collection period. Lack of time was the major reason given by the few who refused to take part in the study. For any selected participant who could not be interviewed during the first contact, an appointment was made for any other convenient time.

\section{Results}

A total of 448 hospital workers participated in this study. Of these, $44.3 \%$ were females. The majority of the workers $(60.1 \%)$ had completed primary school and less than $16 \%$ were university graduates (Table 1 ).

Work tenures in the hospital amongst participants ranged from one to 35 years. Approximately 54\% of the study respondents were supporting staff such as cleaners, messengers, clerks, administrators and drivers, and approximately $15 \%$ were medical doctors. About $25 \%$ of the respondents had leadership positions at various levels in the hospital. Almost $70 \%$ had applied for the job that they were doing. However, it was not clear what proportion of workers had been employed for other jobs and later changed to what they were doing during the study period. For example, some nurses were collecting money, a task normally conducted by people trained in revenue collection. Only one respondent indicated that their major motive for applying for the job was to make money. Many workers $(56 \%)$ indicated that they wanted to work in the hospital to serve people and $20 \%$ were simply seeking employment of any kind. Ten percent of the workers said they applied for the job because of professional prestige.

\section{Extent of Job Satisfaction}

Respondents in this study were asked about the extent to which they were satisfied with the work they were doing in the hospital and the response pattern obtained is summarized in Table 2.

Although more than half of the workers indicated that they were satisfied with their work, a significant number $(45.1 \%)$ were unsatisfied, with clinical support workers such as laboratory technicians and pharmacists reporting the most dissatisfaction of any group. When the reported level of satisfaction was examined across different levels of education, it was found that those with primary school education showed the highest proportion (61\%) of respondents who were satisfied with their job. This group comprised mainly those involved in manual work such as cleaners and drivers. This finding was not surprising since many respondents in this category could not easily obtain alternative employment within or out of the country.

For those who were not happy with their jobs, three main reasons were given. Low salaries were cited by $73.3 \%$ of the supporting staff, $66.7 \%$ of the nurses, $63.3 \%$ of the doctors, and $54.5 \%$ of other clinical staff. Factors related to the working environment were the second major reason for low motivation in the hospital, and were more prominent among clinical support staff $(50 \%)$, followed by doctors $(36.7 \%)$, supporting staff $(35.8 \%)$, and nearly $17 \%$ of the nurses. Inadequate facilities for performing expected tasks were cited as the third major factor in causing low morale at work. This problem was cited by nearly $38 \%$ of respondents in the category of other clinical staff, almost one third of the nurses, and nearly $27 \%$ of doctors. Although details on this particular factor were not collected, some respondents reported that it was not unusual for some prescribed drugs to be out of stock and some diagnostic tests not done due to lack of reagents or other important supplies, particularly for a national referral hospital.

Nearly one third of the nursing staff and almost $29 \%$ of doctors were dissatisfied to the extent of considering resignation from their positions, as were $22 \%$ of supporting staff, and $18 \%$ of other clinical support workers such as laboratory technicians, pharmacists and radiological assistants.

An attempt was made by the hospital to identify key factors influencing staff motivation and performance that were amenable to intervention. These included awareness of job description through performance evaluations and feedback, as well as the administration of rewards and punishment for work-related behaviours. On-the-job training and intra-organizational communication, as well as the extent to which the worker felt cared for were also targeted.

Table 1: Demographic distribution of the study sample by sex.

\begin{tabular}{lccc}
\hline \multirow{2}{*}{ Demographic Characteristic } & \multicolumn{2}{c}{ Sex } & \\
\cline { 2 - 3 } & Male & Female & Total \\
\hline Age (Years): & 28.8 & 34.6 & 32.0 \\
$<40$ & 41.9 & 45.5 & 43.9 \\
$40-50$ & 29.3 & 19.9 & 24.1 \\
$>50$ & & & \\
& 58.8 & 61.1 & 60.1 \\
Level of Education: & 17.1 & 29.6 & 24.0 \\
Primary School & 24.1 & 9.3 & 15.9 \\
Secondary School & & & \\
University & & & \\
& 23.0 & 9.3 & 15.4 \\
Professional Category: & 5.6 & 39.4 & 24.4 \\
Doctors & 6.6 & 0.1 & 6.3 \\
Nurses & 64.8 & 45.1 & 53.8 \\
Other Clinical Support & & & \\
Other Supporting Staff & & & \\
\hline
\end{tabular}


Table 2: Percentage Distribution of Levels of Job Satisfaction by Professional Background of the Hospital Workers

\begin{tabular}{lccccc}
\hline \multirow{2}{*}{$\begin{array}{l}\text { Level of } \\
\text { Satisfaction }\end{array}$} & Doctors & Nurses & $\begin{array}{c}\text { Other } \\
\text { Clinical } \\
\text { Staff }\end{array}$ & Others & Total \\
\cline { 2 - 5 } & 4.4 & 2.8 & 3.7 & 7.6 & 5.7 \\
\hline Very satisfied & 45.6 & 47.7 & 29.6 & 53.2 & 49.2 \\
\hline Satisfied & 41.2 & 39.3 & 59.3 & 34.2 & 38.0 \\
\hline Unsatisfied & 8.8 & 10.3 & 7.4 & 5.1 & 7.1 \\
\hline Very unsatisfied & $\mathbf{1 0 0 . 0}$ & $\mathbf{1 0 0 . 0}$ & $\mathbf{1 0 0 . 0}$ & $\mathbf{1 0 0 . 0}$ & $\mathbf{1 0 0 . 0}$ \\
\hline Total & & & & & \\
\hline
\end{tabular}

Assessment of Work Performance and Feedback

Before requesting information on work performance, respondents were first asked if a job description was supplied to them when first employed. The majority $(72.3 \%)$ reported that this was the case, however, the answers varied considerably according to professional level. While only $38 \%$ of doctors received a job description, nearly $94 \%$ of nurses, over $73 \%$ of supporting staff, and $64.3 \%$ of other clinical support workers received such information when they were employed.

With regards to evaluation of tasks performed, only $60 \%$ of the workers indicated an awareness of the criteria used for evaluating their work performance; of these, doctors as a group had the lowest $(40.9 \%)$ proportion followed by workers in the other clinical support category. Evaluation of job performance was found to be infrequent. Over 57\% underwent annual job evaluations while nearly $27 \%$ reported that their work had never been evaluated. Despite these figures, lack of feedback regarding work output was a source of dissatisfaction, particularly amongst the doctors. Only $28.6 \%$ of doctors indicated that they had received adequate performance review compared to $62 \%$ of nurses and almost $67 \%$ of supporting staff.

\section{Rewards and Punishment at Work}

The working environment in the hospital in this study appeared to be characterized by punishment for inappropriate work-related behaviour rather than by rewards for good work performance. Only $18 \%$ of the study respondents reported positive reinforcement from their employer, while nearly $78 \%$ reported that punishment for inappropriate work-related behaviour was fairly common. Verbal and written warnings were the most common types of punishment used. Reasons for the wide disparity between rewards and punishment in the work environment were not explored in this study, but this finding highlighted an important feature of workplace management in the study setting.

\section{Participation in Decision Making}

When interviewed about their participation in hospital decision-making processes, nearly half of the study respondents reported a lack of input into discussions regarding ways to improve work output; almost $40 \%$ of the doctors and $36.2 \%$ of the nursing staff gave this response. In addition, over $48 \%$ of other clinical support staff and
$58 \%$ of supporting staff revealed that meetings to discuss work-related issues with management were rare.

Furthermore, given the importance of interaction between different work units in maintaining and improving patient services, respondents were asked to comment on the opportunity for such meetings; the responses are summarized in Table 3.

Table 3: Frequency of Joint Meetings Between Different Departments According to Worker's Professional Background

\begin{tabular}{|c|c|c|c|c|c|}
\hline \multirow{2}{*}{$\begin{array}{c}\text { Meeting } \\
\text { Frequency }\end{array}$} & \multicolumn{4}{|c|}{ Professional background } & \multirow[t]{2}{*}{ Total } \\
\hline & Doctors & Nurses & $\begin{array}{c}\text { Other } \\
\text { Clinical } \\
\text { Support }\end{array}$ & $\begin{array}{c}\text { Supporting } \\
\text { Staff }\end{array}$ & \\
\hline Never & 45.6 & 22.9 & 33.3 & 43.2 & 38.8 \\
\hline Rarely & 29.4 & 30.5 & 25.9 & 24.4 & 26.7 \\
\hline Sometimes & 13.2 & 8.6 & 14.8 & 15.4 & 13.4 \\
\hline Most of the time & 11.8 & 11.4 & 3.7 & 4.3 & 7.1 \\
\hline Don't know & 0.0 & 26.7 & 22.2 & 12.8 & 14.7 \\
\hline Total & 100.0 & 100.0 & 100.0 & 100.0 & 100.0 \\
\hline
\end{tabular}

Generally, such meetings within or between departments were rarely or never held. This was particularly the case among doctors (75\%) and supporting staff $(67.6 \%)$ of the hospital. For example, doctors from different departments and specialties would be expected to meet to resolve clinical care problems, and regular communication between clinical and supporting staff would be similarly necessary to maintain the smooth delivery of services. This finding was therefore somewhat surprising given the complex nature of a hospital working community and the need for effective communication across the board to improve patient care and to minimize workers dissatisfaction. The lack thereof suggests that many problems requiring joint discussion remained largely unresolved, providing a major source of frustration for staff and inefficiency in the expected outputs.

\section{Information Flow to and From Hospital Management}

Smooth information flow in a hospital is vital to maximize efficiency and minimize personnel problems. Government circulars on staff welfare are periodically sent to hospital management on the assumption that such information will be passed on to the workers. However, this study revealed that less than $19 \%$ of workers at $\mathrm{MNH}$ across all categories can access such information. The problem appeared to be particularly serious among doctors with only $7.5 \%$ of doctors reporting that information from the government was easily accessible. Nurses were slightly more satisfied than doctors in this regard with $25.9 \%$ reporting good access to relevant information, along with $18.9 \%$ of supporting staff. Consequently, unsupported rumors and corridor gossips were common amongst the hospital staff, perhaps accounting for the frequent work strikes in the hospital. Lack of effective communication channels between hospital management and workers has created an environment where "word of mouth" was among major methods through which information was disseminated among workers. 


\section{Perceived Concern by Management for Worker Welfare}

Lack of concern by employers for staff welfare was found to be a negative indicator for both motivation in the workplace and overall work performance. A large majority of the workers in this study $(88 \%)$ felt that their employer did not care about their welfare: $82.4 \%$ of the doctors, $90.7 \%$ of the nurses, $85.7 \%$ of other clinical support workers, and $87.9 \%$ of supporting staff. This finding also generally reflected how the hospital workers perceived the interest or concern in personnel issues by the hospital management. Finally, a fairly negative view was reported by workers with respect to the attitude of the employer to allow days off for a worker with a sick spouses or child. Also, assistance from the hospital management to sick workers was rated as unsatisfactory to some extent by nearly $88 \%$ of the workers and such negative feelings were most prominent among the doctors $(91.2 \%)$, followed closely by the nursing staff $(90 \%)$ and other clinical support staff $(76.5 \%)$.

\section{Discussion}

A comprehensive study of the $\mathrm{MNH}$ was recently undertaken as part of more wide-ranging reforms of the health system in Tanzania. Effects of recent and ongoing reforms were identified and analyzed, and recommendations were made based on the findings to seek further improvement to the country's system of providing efficient and adequate clinical care. Here, we report on the status of personnel satisfaction and motivation amongst workers at the Hospital, one of the major components of the overall study. Interviews conducted on a representative sample of all employees revealed a general dissatisfaction with their work. This finding applied to more than half of the doctors and nurses, two-thirds of other support staff and over one-third of supporting staff.

The reported level of satisfaction did not correlate with gender or professional background, but did show a negative correlation with level of education. The factors associated with the general lack of motivation were further explored to reveal problems with task descriptions and feedback, acknowledgment and reward for good service, communication at all levels, poor facilities affecting patient care, and a perceived lack of concern by the hospital management for the welfare of the workers. Together, these factors generally undermine the work output of the Hospital with the potential to significantly compromise the provision of clinical care.

When initially asked why they were dissatisfied with their work, the study respondents cited 3 main reasons, which were low salaries or reward, problems in the working environment and inadequate facilities for performing expected tasks. A significant number of workers in all categories reported that they had considered resigning from the hospital because of these reasons. This study highlights and confirms earlier research that low motivation amongst workers is a major factor in clinical staff leaving rural areas for the city or leaving the country altogether $(20,23)$.
The findings from this study indicate a need for the hospital management to address weaknesses identified and implement recommendations to improve the morale of workers. Although pay conditions were amongst the factors contributing to low motivation, the study showed that this was only part of a larger and more complex problem. Based on the extensive survey of personnel reported here, several recommendations are proposed.

First, the hospital management needs to set clear performance goals and job descriptions for workers at all levels. The goals should form a basis for the evaluation of tasks completed, both by the workers themselves and by management. Positive reinforcement should be administered for work well done.

Second, comprehensive performance evaluations should be conducted frequently and appropriate reinforcement given for good service with less focus on punitive measures.

Third, salary increases or promotion should be regularly considered to reward good performance. However, alternative forms of reinforcement should also be introduced and used frequently, including verbal reinforcement, letters of recognition for tasks performed well, priority for short- and long-term training for workers who excel in their performance, and creating an environment where good service generates self-motivation for the workers.

Fourth, there is need to initiate mechanisms to improve communication amongst workers in different units and between management and workers. This may involve improving internal telephone communication, developing a better communication system for night-workers such as providing mobile phones, increasing the frequency of meetings within and across departments, and reviewing the mechanisms for disseminating information to workers to reduce 'corridor' gossip as the main means of information being passed on.

Furthermore, there is need to improve perception by workers of concern for their welfare, particularly with regard to meal breaks, assistance given to sick workers or their close relatives, and better conduits for interaction among workers themselves and between workers and management at various levels (for example, through sporting or social events).

Finally, there is need to improve the availability and quality of hospital equipment and supplies at all levels. The extent of workers motivation in health care facilities in Tanzania is not known and there are very few studies which have addressed this challenge. However, available reports show that the country has only about a third of required human resource mix in the health sector (25). Migration of these workers partially due to poor motivation is among factors which make workers migrate from rural to urban areas and from the country to other countries where workers perceive they could get better job satisfaction than available alternatives. There is a need for more empirical data on health workers job satisfaction from other health facilities in both rural and urban areas in order to contribute towards required information for interventions targeting improvement of health services to which workers motivation is among important inputs. 


\section{Acknowledgements}

The authors wish to acknowledge the financial support given by Axios for conducting this study. We would also like to thank our research assistants who collected the data on which this paper is based as well as workers from the Muhimbili National Hospital whose cooperation facilitated generation of information for this study. We also thank Axios for technical assistance and support in writing this paper.

\section{Conflict of interest:}

We declare that there was no conflict of interest with the source of funds used for conducting this study or the hospital where the study was based.

\section{References}

1. Mathauer, I and Imhoff, I Health worker motivation in Africa: the role of nonfinancial incentives and human resource management tools Human Resources for health 2006; $4: 24$

2. WHO, Working together for health: The World Health Report 2006, The World Health Organization, Geneve, 2006a.

3. Dovlo, D Wastage in the health workforce: some perspectives from African countries. Human Resource for Health; 2005 3:6

4. Kober, K and Damme, WV Public sector nurses in Swaziland: can the downward trend be reversed? Human Resources for Health 2006; 4:13.

5. Auliffe, EM and Maclachlan, M Turning the Ebbling Tide: Knowledge Flowa and Health in Low-income Countries Higher Education Policies 2005; 18, 231242.

6. United Nations, The Millennium Development Goals Report 2007, United Nations, NewYork 2007.

7. Lethbridge,J Public Sector Reform and demand for Human Resources for $\mathbf{H}$, Human Resources for Health 2004; 2:15.

8. Dussault G and Dubois,C Human Resources for Health Policies: a critical component in health policies Human Resources for Health 2003; $1: 1$.

9. WHO, Taking Stock: Health worker shortages and the response to AIDS. HIV?AIDS Programme, World Health Organization, 2007.
10. Ssengooba, F; Rahman, SA; Hongoro, $\mathrm{C}$ et.al; Health sector reforms and human resources for health in Uganda and Bangladesh: Mechanism of effect. Human Resources fro Health 2007; 5:3.

11. Dieleman, $\mathbf{M}$; Toonen, $\mathbf{J}$ Toure, $\mathbf{H}$ et.al; The match between motivation and performance management of health sector workers in Mali. Human Resource for Health 2006; 4:2.

12. Fritzen, S Strategic management of the health workforce in developing countries: what have we learned? Human resources for Health 2007; 5:4.

13. Bennett,S and Franco,LM. Public Sector Health Workers motivation and Health Sector Reform: A conceptual Framework. Partnership for Health Reform, Major Apllied Research 5, Technical paper No1, January 1999.

14. Lindner, JR, Understanding Employees Motivation, Journal of Extension Vol.36 No3 1998.

15. Kanfer, R. Measuring Health Workers Motivation in Developing Countries. Partnership for Health Reforms, Major Applied Research 5 working [paper No1, January, 1999.

16. Manongi,RN; Marchant, TC and Bygbjerg, IC Improving motivation among primary health care workers in Tanzania: A health worker perspective. Human Resources for health 2006; 4:6.

17. Dusssault, G and Franceschine, MC. Not enough there, too many here: understanding geographical imbalances in the distribution of the health workforce. Human Resources for Health 2006; 4:12.

18. Dieleman, M, Cuong, PV; Anh, LV et.al; Identifying factors for job satisfaction for rural health workers in Viet Nam. Human resources for Health 2004, $1: 10$.

19. USAID. The Health Sector Human Resource Crisis in Africa: An issue paper United States Agency for International Development, Bureau for Africa, 2003.

20. 20.Van Lerberghe, W., Conceicao, C., Van Damme, W., et.al (2002) When staff is underpaid: dealing with the individual coping strategies of health personnel. Bulletin World Health Organisation 2002; 80(7), 581-584.

21. Habte, D., Dussault, G., \& Dovlo, D. Challenges confronting the health workforce in sub-Saharan Africa. World Hosp Health Services 2004; 40, 23-26.

22. High Level Forum. Addressing Africa's Health Workforce Crisis: An avenue for action. . High Level forum on the Health MDGs, Abuja December, 2004.

23. Liese, Blanchet \& Dussault, The Human Resource Crisis in Health Services in Sub-Saharan Africa, Background paper for the World Bank, September 15th, 2003.

24. Kireria,AM and Ngowi, D Assessment of the human and financial resources for the revised HIV/AIDS National Multi-sectorial Strategic Framework (NMSF) Final Report. Tanzania Commission for AIDS, 2007.

25. MoH, Human Resources for Health Strategic Plan 2008-2013; Ministry of Health and Social Welfare, United Republic of Tanzania, 2008.

26. Sanders, DM; Todd and Chopra, Dyer, M Confronting Africa's Health Crisis: More of the same will not be enough. BMJ 2005; 331:755-758.

27. Dyer, $O$. UN predicts that the Millennium Development Goals will be missed by a wide margin in Africa. BMJ 2005; 330(7504):1350.

28. Chen, L, Evans, T., Anand, S., Boufford, J.I., et.al. (2004) Human resources for health: overcoming the crisis. Lancet 2004; 364; 1984-1990. 